\title{
A importância histórica e social da infância para a construção do direito à saúde no trabalho
}

\section{The historic and social importance of childhood for the construction of the right to health at work}

\author{
Valdinei Santos de Aguiar Junior \\ Fundação Oswaldo Cruz. Escola Nacional de Saúde Pública Sérgio \\ Arouca. Rio de Janeiro, RJ, Brasil. \\ E-mail: vival_rjळhotmail.com

\section{Luiz Carlos Fadel de Vasconcellos} \\ Fundação Oswaldo Cruz. Escola Nacional de Saúde Pública Sérgio \\ Arouca. Departamento de Direitos Humanos, Saúde e Diversidade \\ Cultural. Rio de Janeiro, RJ, Brasil. \\ E-mail: fadelळensp.fiocruz.br
}

\section{Resumo}

0 reconhecimento do trabalho infantil enquanto problema social que compromete saúde e educação das crianças começa a despontar juridicamente no final do século XVIII e prossegue por todo o século XIX estabelecendo, pouco a pouco, regramentos jurídicos para impedir ou atenuar sua continuidade. A construção de uma normativa jurídica de proteção à infância está histórica e intimamente atrelada ao processo de regulação e proibição do trabalho de crianças nas sociedades industrializadas. Esse processo culmina na configuração de uma concepção de infância apartada do mundo do trabalho, mas, contraditoriamente, a ele atrelada. Este texto tem como objetivo estabelecer uma relação entre a evolução da norma protetiva da saúde no trabalho e a mudança de concepção de infância, tendo como panorama de análise o contexto sócio-histórico do Reino Unido no período entre 1788 e 1879 , em que importantes leis trabalhistas foram publicadas visando a impor regras ao emprego de crianças. Verifica e sublinha que o próprio avanço da norma trabalhista referente à saúde foi decorrente do olhar sobre o trabalho infantil nas indústrias. A metodologia utilizada foi a revisão bibliográfica sobre infância, trabalho infantil e análise de documentos oficiais, principalmente do período especificado. Os resultados demonstram a importância da infância na mudança do contrato social com foco na relação saúde-trabalho; a transição de um trabalho fabril para o trabalho escolar; e a evidência de que as crianças são sujeitos ativos e coprodutores da realidade social.

Palavras-chave: Infância; Relação Saúde-Trabalho; Trabalho Infantil; Normas Trabalhistas. 
The recognition of child labor as a social problem that compromises the health and the education of children begins to emerge legally at the end of the eighteenth century and continues throughout the nineteenth century establishing legal regulations to prevent or mitigate its continuity. The construction of a legal framework for child protection is historically and closely linked to the process of regulation and prohibition of child labor in industrialized societies. This process culminates in the configuration of a conception of childhood that is separate from the world of work, but, contradictorily, linked to it. This text aims to establish a relationship between the evolution of the protective standard of health at work and the change of conception of childhood, having as a panorama of analysis the socio-historical context of the United Kingdom in the period between 1788 and 1879, in which important Labor laws were published in order to impose rules on the employment of children. It verifies and emphasizes that the very advance of the labor norm related to health was due to the look on child labor in industries. The methodology used was the bibliographical revision on childhood, child labor and analysis of official documents mainly of the specified period. The results demonstrate the importance of childhood in changing the social contract with a focus on the work-health relationship; the transition from factory work to school work; and the evidence that children are active subjects and coproducers of social reality. Keywords: Childhood; Relationship Between Health and Work; Child Labor; Labor Standards.
A questão do "trabalho infantil" - sua proibição jurídica e os esforços no sentido de erradicá-lo do mundo - é pauta fundamental nas agendas políticas internacionais do século XXI. Desde a criação da Organização Internacional do Trabalho (OIT), ainda no primeiro quarto do século XX, convenções e recomendações vieram sendo publicadas versando sobre idades mínimas para o emprego em determinados setores de atividades produtivas, demonstrando que a especificação de idades mínimas é uma regra fundamental da legislação trabalhista e estabelecendo a necessidade dessa regra ser aplicada internacionalmente. Porém, somente em 1973 a OIT (1999) viria a reconhecer, com a Convenção 138, a necessidade de que as idades mínimas fossem aplicadas a qualquer tipo de atividade de trabalho e, com a Convenção 182 de 1999, enfatizar a necessidade de se erradicar o trabalho infantil do mundo, sobretudo o trabalho em "suas piores formas".

Dados apresentados em 2013, pela ocasião da III Conferência Global do Trabalho Infantil, sediada no Brasil, apontavam uma constante redução dos índices de trabalho infantil ocorrida nas últimas décadas, mas evidenciando que ainda é grande o número de crianças que trabalham no mundo: cerca de 168 milhões de crianças, sendo que, destas, aproximadamente 86 milhões inseridas naquelas consideradas "piores formas de trabalho infantil" (OIT, 2013).

A principal justificativa sobre a necessidade e urgência da erradicação do trabalho infantil é o dano que o trabalho causa à saúde e ao desenvolvimento físico, psicológico e social de crianças e adolescentes. Contudo, o fenômeno da exploração do trabalho de crianças e adolescentes e suas proporções refletem a dimensão prejudicial e injusta da organização social do trabalho no mundo que contraria o que preconiza a Declaração Universal dos Direitos da Criança, de 1959 - que a humanidade deve o melhor de seus esforços às crianças.

Ainda assim, verifica-se que, nos últimos dois séculos, de uma forma geral, o direito internacional e as legislações nacionais promoveram e instituíram direitos que visam a garantir condições mais dignas e justas à vida de crianças e adolescentes 
(Vianna, 2004; Santos, 2007; Liberatti; Dias, 2006); assim como direitos que visam a garantir relações e condições de trabalho também mais dignas e justas. Entre as conquistas e avanços referentes aos direitos relacionados ao trabalho, são essenciais aqueles que se referem ao direito à saúde no trabalho. Depreende-se, então, que as políticas referentes ao trabalho infantil, à medida que visam a retirar as crianças da situação de trabalho, conjuguem, em tese, dois objetivos: garantir melhores condições de saúde na infância e garantir uma organização social do trabalho mais justa. Contudo, o percurso nos mostra que essas medidas não foram totalmente suficientes.

Cabe então rememorar que, no auge da Revolução Industrial inglesa, o trabalho de crianças foi amplamente utilizado nas indústrias têxteis e, consequentemente, conferiu notoriedade aos problemas ocasionados pela intensa exploração e pela inserção precoce de crianças e adolescentes no trabalho industrial. Ainda durante o século XIX, pouco a pouco, leis foram sendo publicadas com a justificativa de reduzir os danos que o trabalho industrial precoce causaria à infância. Esse processo que então se inicia, de gradual retirada das crianças do mundo do trabalho, foi decisivo para o desenvolvimento e para a consolidação da concepção de infância vigente nas sociedades modernas industrializadas.

À medida que a infância veio sendo retirada dos postos de trabalho, consolidou-se a necessidade de expandir a obrigatoriedade da escolaridade, e a escola veio assumindo, assim, a função de legítima instituição socializadora das crianças (Stearns, 2006; Postman, 2012; Corsaro, 2011). Assim, a partir da utilização da infância no trabalho nas indústrias e a consequente percepção social de que essa prática acarretava prejuízos à sua saúde e a seu desenvolvimento, a imposição de regras e limites à exploração do trabalho infantil está no fundamento histórico de um Direito Infanto-Juvenil que instituiu a concepção de que crianças e adolescentes exigem direitos e proteções especiais (Vianna, 2004; Santos, 2007; Liberatti; Dias, 2006).

Porém, destacamos neste artigo que não somente as mudanças na organização do trabalho foram cruciais para a definição de direitos referentes à infância, mas que a participação da infância foi fundamental para a definição de direitos referentes ao trabalho, especialmente no que se refere ao direito à saúde. Em pesquisa realizada a partir da análise de obras que examinaram o contexto socioeconômico em que foram publicadas importantes leis trabalhistas inglesas do século XIX, verificamos que a infância, enquanto categoria estrutural da sociedade, foi crucial e decisiva na gênese do direito à saúde no trabalho. Apesar de atualmente o trabalho ser considerado prejudicial à infância e uma função social juridicamente destinada a adultos, foi a presença da infância no trabalho nas fábricas que fundamentou os primeiros documentos legais que visavam a garantir aos trabalhadores - de todas as idades - melhores condições de saúde no trabalho. Assim, este texto apresenta uma reflexão sobre a importância histórica e social da infância na construção do direito à saúde no trabalho. Essa reflexão, que reconhece a infância enquanto categoria ativa na construção da realidade social, possibilita o aprofundamento de questões relevantes para a análise da exploração do trabalho na infância e contribui para a ampliação e para o enriquecimento das perspectivas sobre a relação saúde-trabalho, uma vez que se debruça sobre a dimensão sócio-histórica do direito à saúde no trabalho considerando a infância enquanto categoria de análise.

\section{Algumas considerações sobre a infância e sua relação com o trabalho}

O termo "infância" pode ser empregado em pelo menos dois sentidos:1) numa dimensão individual, referindo-se a um período da vida da pessoa, etapa do desenvolvimento humano; 2) numa dimensão coletiva, referindo-se ao coletivo de crianças de uma sociedade, categoria na estrutura social (Qvortrup, 2010; Corsaro, 2011). Seja enquanto período ou enquanto categoria, análises e teses históricas e sociológicas demonstram que a infância é socialmente construída e verificam que as reconfigurações e as funções sociais da infância se relacionam às transformações do mundo do trabalho nos contextos históricos (Ariès, 1981; Corsaro, 2011; Postman, 2012; Qvortrup, 2011a; 2011b; Stearns, 2006). 
Corsaro (2011) sublinha que a infância, em sua conotação individual, é o período socialmente construído em que a criança vive sua vida. No Brasil, o Estatuto da Criança e do Adolescente (ECA), Lei ${ }^{\circ}$ 8.069, de 13 de julho de 1990, considera como criança "a pessoa até doze anos de idade incompletos, e adolescente aquela entre doze e dezoito anos de idade" (Brasil, 1990, art. $2^{\circ}$ ). Entretanto, na normativa internacional referente ao trabalho infantil encontramos a definição da OIT que determina que “o termo 'criança' designa toda pessoa menor de 18 anos" (OIT, 1999 , art. $2^{\circ}$ ). Neste texto optamos por utilizar o termo "infância" com a abrangência considerada pela OIT, com referência ao coletivo de crianças e adolescentes. Essa opção não desconsidera as diversas especificidades de cada uma das etapas do desenvolvimento nesse período etário, mas busca agregar, sob o único termo "infância", a compreensão de aspectos compartilhados, como a menoridade e a necessidade de socialização e preparação para o mercado de trabalho, visando, inclusive, a contemplar uma perspectiva histórica da infância, visto que Ariès (1981, p. 41) observou que "até o século XVIII, a adolescência foi confundida com a infância”.

Segundo Qvortrup (2010; 2011a; 2011b), reconhecer a participação e a importância da infância ainda é, de uma forma geral, uma perspectiva pouco considerada tanto na produção acadêmica quanto nas decisões políticas e econômicas das sociedades em geral. Demonstra, assim, que é possível e necessário conectar a infância às análises sociais e econômicas, incluindo-a e compreendendo-a como uma categoria coprodutora da realidade social. Sobre a compreensão do trabalho de crianças, Qvortrup defende a ideia de que elas não deixaram de trabalhar - ou seja, de participar ativamente na estrutura social por meio de uma atividade produtiva - na sociedade moderna, mas tão somente tiveram a natureza de seu trabalho e participação social transformada. Assim, considera que o trabalho escolar é uma forma de trabalho e, como sublinha, de fundamental importância na manutenção das economias nacionais (Qvortrup, 2010; 2011a; 2011b).

Stearns (2006) compreende que a história mundial da infância está intimamente vinculada à organização social do trabalho. 0 papel das crianças veio se redefinindo, durante toda a humanidade, de acordo com a relação que as crianças e suas famílias tiveram com o trabalho. Conforme foi mudando a predominância dos modos de produção das sociedades na história, mudaram, também, a participação e a importância social da infância, bem como variou a proporção de crianças no contingente populacional das sociedades (Stearns, 2006; Qvortrup, 2011b). Assim, em todas as sociedades, a configuração da infância esteve, direta ou indiretamente, atrelada às reconfigurações do mundo do trabalho, sendo a redução do trabalho infantil, a redução da mortalidade infantil e o decréscimo no quantitativo de filhos por família os fatores que fundamentam o "modelo moderno de infância” (Stearns, 2006). Uma mudança crucial na concepção de infância e nas relações e práticas das famílias com suas crianças é que, com a proibição do trabalho infantil e a obrigatoriedade da escolarização e preparação para o trabalho assalariado na fase adulta, as crianças deixaram de ser ativos econômicos (que poderiam contribuir na renda familiar) e passaram a ser passivos econômicos (as famílias deveriam investir na sua formação) (Stearns, 2006).

Qvortrup (2011a) observa que na transição da participação das crianças nas economias nacionais, as famílias passam a investir na formação das crianças, mas é sobretudo a sociedade empresarial que se torna a beneficiária desses investimentos (em termos de força de trabalho futura); e destaca que, apesar das justificativas lógicas e morais que sustentam a escolarização, é necessário considerarmos e avaliarmos criticamente o fato de que, com a evolução da sociedade industrial, o "Estado tem tomado para si o trabalho e/ou o tempo das crianças" (Qvortrup, 2011a, p. 326). Dessa forma, é possível se verificar o quão sintomático pode ser o pouco reconhecimento da participação efetiva das crianças na estrutura social. Ao enfatizar a tese de que as crianças não pararam de trabalhar, destacando o exemplo do trabalho escolar como a forma que o Estado tomou para si o trabalho e tempo das crianças, Qvortrup enfatiza que “as crianças, como resultado de seus próprios esforços, merecem ser contempladas com uma quota justa de recursos sociais” (Qvortrup, 2011a, p. 326). 
Sob a perspectiva das crianças enquanto sujeitos ativos e coprodutores da realidade social (Qvortrup; 2010; 2011a; Corsaro, 2011;) e da compreensão das transformações históricas da relação infância-trabalho (Stearns, 20o6; Corsaro, 2011), analisamos como se instituíram as leis que vieram regulamentando o trabalho de crianças no século XIX, até chegar ao objetivo de "erradicar o trabalho infantil" no século XX. O que verificamos é que, a par da imprescindível proteção da infância contra os danos causados pela exploração da sua força de trabalho, as mudanças de paradigma da relação infância-trabalho ocorridas depois do advento do modo de produção industrial fabril também propiciaram, por um lado, uma relativa invisibilidade da efetiva participação social das crianças e, por outro, uma valoração negativa do termo "trabalho", calcado na associação entre trabalho e pobreza (Aguiar Junior, 2015).

Nas sociedades pré-industriais, a infância e o trabalho eram fenômenos conciliáveis (Qvortrup, 2011b; Stearns, 2006). É sobretudo necessário sublinharmos que, se com o avanço das sociedades industrializadas a infância e o trabalho vieram a ser dissociados e enunciados enquanto fenômenos inconciliáveis, nos primórdios do processo de industrialização as crianças tiveram um papel fundamental para o advento e consolidação do então novo modo de produção, visto que integraram ativa e numerosamente a composição da força de trabalho nas indústrias têxteis. Do mesmo modo, tiveram um papel essencial quanto à imposição de regras que limitassem a capacidade do sistema industrial de exploração do trabalho e da saúde da classe trabalhadora, pois sua presença nas fábricas evidenciava a exploração e os danos à saúde.

Em suma, a participação das crianças no trabalho nas indústrias têxteis, por um lado, possibilitou inicialmente o "sucesso das indústrias" - como reconhece o site do parlamento inglês (United Kingdom, [201-?], tradução nossa') -, potencializando a capacidade de acumulação de capital e, por outro lado, foi o fundamento crucial para a instituição de uma normativa jurídica de proteção à saúde no trabalho.

\section{Procedimentos metodológicos: delimitação, sistematização e análise}

Nossa pesquisa e reflexão se fundamentaram em duas etapas: a) busca, sistematização e leitura de leis britânicas do século XIX que versassem sobre o trabalho de crianças e que serviram de base para a legislação trabalhista subsequente; e b) análise de obras que abordaram o contexto do período em que as referidas leis foram publicadas, bem como possíveis causas e efeitos das publicações dessas leis. A opção pelo recorte histórico-geográfico se deveu pela reconhecida importância e influência que a Revolução Industrial inglesa veio a exercer sobre o desenvolvimento político e econômico das sociedades modernas industrializadas e na gênese do direito internacional trabalhista. No corpus de leis que especificaram o período a ser analisado, figuram principalmente as Leis de Fábricas (Factory Acts), mas também foram elencadas e analisadas outras leis que abordam a relação entre infância e trabalho.

As leis foram obtidas com a consulta à internet, principalmente nos seguintes portais eletrônicos oficiais: The oficial home of UK legislation, The UK Parliament, The National Archives of UK (United Kingdom, [201-?]) e The Irish Statutes Books. Depois da organização das leis e documentos encontrados nos endereços oficiais, delimitamos o contexto histórico a ser analisado (que compreende o período entre 1788 e 1889) e, então, buscamos analisar o contexto socioeconômico, sobretudo visando a compreender a concepção jurídica da relação entre trabalho e infância nesse período.

Apesar da lei Health and Moral Act de 1802 (United Kingdom, 1802) ter sido considerada marco inaugural da legislação trabalhista por sua importância histórica na regulação do trabalho nas indústrias têxteis, optamos por iniciar nosso recorte temporal no ano de 1788, data de publicação da Chimney Sweepers Act por esta ter sido uma lei que especificou uma idade mínima (oito anos) para o uso do trabalho de crianças aprendizes na limpeza de chaminés. Delimitamos até o ano de 1889 por ter 
sido o ano de publicação da lei Prevention to cruelty, and better protection of children Act, em que o intuito de proteção de crianças é então apresentado em lei sem estar mais especificamente vinculado à questão de regras trabalhistas.

Ao sistematizarmos e analisarmos os textos selecionados, buscamos verificar o que as leis especificaram, quais foram as características do seu contexto de publicação, suas causas e efeitos, buscando respostas para quais foram os limites etários especificados e quais foram as regras estabelecidas referentes à participação de crianças (menores) no trabalho. Constatamos que: a) a primeira lei referente ao trabalho nas fábricas não visou a tirar as crianças das indústrias têxteis mas, provavelmente tendo em vista os notórios prejuízos à sua saúde, estabeleceu regras e condições de trabalho que melhorassem as condições de saúde das crianças (aprendizes) no trabalho; b) posteriormente, num cenário de continuidade da exploração da força de trabalho das crianças, as leis começaram a especificar limites de idade para o emprego de crianças nas indústrias; c) as regras expostas já na lei de 1802, à medida que buscavam mudanças nos ambientes de trabalho das indústrias, visavam a melhores condições de saúde, extensivas aos demais trabalhadores (adultos); d) a presença de crianças nas indústrias, bem como as consequências à sua saúde ocasionadas pela exploração de seu trabalho, foi o primeiro e o principal motivo para a construção do regramento jurídico trabalhista.

\section{Reflexão: achados e discussão}

\section{A relação entre a concepção de infância $e$ trabalho nas indústrias}

Os danos causados à saúde dos trabalhadores no então novo sistema industrial, na Inglaterra da segunda metade do século XVIII, evidenciou a dimensão cruel da exploração da força de trabalho que ali se instaurou. As indústrias passaram a apresentar doenças e acidentes relacionados ao trabalho, evidenciando que os jovens das regiões industriais apresentavam mais deformidades físicas, inclusive diminuindo sua esperança de vida (Andersen, 1969). Em especial, quando, no escopo das análises histó- ricas, sublinham-se os dados sobre a participação das crianças nas fábricas inglesas, pode-se atentar para as condições degradantes e indignas a que estiveram submetidas a classe pobre trabalhadora. Observamos que nem mesmo a infância, hoje reconhecida como uma fase da vida que requer proteção especial, foi protegida das agruras da nova organização do trabalho na sociedade industrial. Mais do que não terem sido protegidas, é necessário enfatizar que as crianças foram amplamente utilizadas no sistema de produção industrial capitalista, sendo de extrema importância para a sua consolidação (Humphries, 2013).

A forma como se concebe a infância na atualidade - a definição de seus limites etários, os tratamentos destinados às crianças, os direitos e deveres sociais das crianças, a natureza de sua participação na estrutura social - difere da concepção de infância que foi vigente na sociedade inglesa nos séculos XVIII e XIX. A seguir, alguns aspectos verificados em nossa análise foram:

1) Escolarização: a obrigatoriedade da escolarização se instituiu juridicamente durante o período analisado, no caso das crianças que trabalhavam, primeiro deixando a responsabilidade do ensino a cargo das indústrias (United Kingdom, 1802) e, posteriormente, repassando a responsabilidade pela oferta do ensino ao Estado e a responsabilidade pelo acesso das crianças à escola e sua permanência às famílias (United Kingdom, 1876). Na época analisada a escolarização que já existia era ainda "privilégio para poucos" (Postman, 2012), e, para grande parte das crianças, o trabalho ainda exercia a função de principal agência socializadora, sendo, para as crianças aprendizes, a escolarização uma incumbência do empregador (United Kingdom, 1802);

2) Contingente populacional e trabalho: a população, de uma forma geral, ainda era muito jovem, e as crianças representavam uma grande proporção do contingente populacional. Na década de 1820, por exemplo, na Inglaterra, a cada cinco pessoas, duas eram crianças (United Kingdom, [201-?]). Com a expansão ilimitada da produção, exploração 
e acumulação do sistema industrial - com a ausência de regras restritivas - não se isentava essa grande parte da população da venda de sua força de trabalho. É importante, sobretudo, enfatizar pelo menos dois aspectos referentes à infância nessa época: a) as crianças eram tratadas e compreendidas como indivíduos socialmente dependentes e relativamente incapazes; e b) a infância precisava ser preparada para a vida adulta, e o trabalho ainda exercia essa função socializadora. Assim, a compra da força de trabalho das crianças se beneficiava com o baixo custo do valor da mão de obra de crianças, tanto pela relação de inferioridade com que eram tratadas quanto pela prerrogativa sustentada pela possível representação social de que empregar uma criança ainda seria um benefício e uma preparação para a vida adulta;

3) Trabalho como educação e fonte de renda: considerando as condições de pobreza a que estavam submetidas, grande parte das crianças eram levadas a trabalhar tanto para complementar a renda familiar quanto como forma de ocupação, educação moral e inserção social. No século XIX, "Era comum para eles trabalharem para complementar a renda familiar", justifica o parlamento inglês (United Kingdom, [201-?]) e acrescenta que para crianças que tinham famílias e especialmente para aquelas que não as tinham, o trabalho era "comum”. "Órfãos e crianças abandonadas passaram a estar sob os cuidados da Lei dos Pobres, porém era comum colocá-los sob os cuidados de empregadores" (United Kingdom, [201-?]);

4) Critérios para definições de idade: não encontramos indícios de que os critérios utilizados para impor os limites de idades nas indústrias tenham sido pautados por características biológicas ou psicológicas da infância enquanto período de vida, reiterando a tese de Qvortrup de que tem sido destinado à infância um "lugar" na estrutura social que é "em termos legais, o lugar da criança como menor dado pelo grupo dominante correspondente, os adultos" (Qvortrup, 2011a, p. 204).
Para tanto, não se faz necessário "ter idades fixadas em termos biológicos, mas definições determinadas socialmente" (Qvortrup, 2011a, p. 204).

Ariès (1981) defende que o sentimento de infância, na forma como hoje é mais ou menos concebido, é uma ideia relativamente recente nas sociedades ocidentais. Ainda que os argumentos de sua tese não sejam unanimemente aceitos, suas proposições sustentam a perspectiva de que as crianças, ao longo da história, receberam tratamentos diferenciados e a forma como hoje a sociedade define a infância - segundo Ariès, como uma fase da vida a ser simultaneamente "paparicada" e "moralizada" e que tem a família e a escola como instituições socializadoras - é uma construção social relacionada a alguns fatores da organização das sociedades modernas. Em nossa análise do desenvolvimento das regras jurídicas relacionadas ao trabalho na sociedade inglesa do século XIX, constatamos que a própria organização social do trabalho é fator crucial na configuração das concepções e das práticas referentes à infância (Stearns, 2006; Qvortrup, 2011a).

É, então, importante atentar sobretudo para a noção de que a participação de crianças nas indústrias não se tratou de um mero acidente de percurso do desenvolvimento industrial e de que o nível de exploração a que elas foram submetidas não foi um aspecto inevitável do desenvolvimento. Em suma, as crianças participaram ativa e efetivamente do trabalho nas indústrias, e essa participação - graças à noção de relativa fragilidade e necessidade de proteção da infância que já vinha se constituindo nas sociedades europeias desde o século XIII (Ariès, 1981) - evidenciou e deu urgência à necessidade da imposição de regras às relações de trabalho.

\section{0 contexto histórico do direito à saúde no trabalho}

Há uma coincidência histórica entre a consolidação do processo da Revolução Industrial e a transição dos Estados absolutos europeus para o que entendemos, hoje, como Estado Moderno. Enquanto se mudava radicalmente o modo de produção social de bens de consumo para uma inédita 
escala industrial, os Estados passavam por transformações políticas profundas nas configurações de seus poderes constituídos, especialmente depois da Revolução Francesa e da independência americana - ambas com a promulgação de cartas de direitos que viriam a servir de paradigmas para os novos Estados e suas cartas regentes, conferindo novos direitos aos cidadãos.

A par disso, decorrido mais de meio século de uma Revolução Industrial, em que os trabalhadores sofriam cruelmente as consequências do novo modo de produção, afetando gravemente sua saúde, os novos direitos de cidadania ainda não haviam alcançado o mundo do trabalho. 0 primeiro esboço de um direito objetivo focado no mundo do trabalho vai surgir na Inglaterra, consignando-se como uma normativa nos moldes das que conhecemos ainda hoje como regramento contratualista das relações de trabalho. Em 1802, o parlamento inglês sanciona o Health and Moral of Apprentices Act.

Considerada como marco legal inaugural do ordenamento jurídico das relações de trabalho instauradas pelo modo de produção industrial capitalista, inaugurado na Inglaterra no século XVIII, essa lei impunha certas regras à utilização da mão de obra das crianças aprendizes nas indústrias, visando a garantir-lhes uma melhor situação de saúde. Por certo, as condições a que eram submetidas as crianças nas primeiras fábricas chamavam a atenção pelo grave comprometimento da sua saúde (Marx, 1988).

Divergências entre os próprios donos das novas fábricas, inclusive nas distintas formas de "cuidar" da sua força de trabalho, criaram um cenário de expectativas quanto a um regramento que estabelecesse padrões de cuidados, medidas e atitudes no trato com a saúde dos trabalhadores. Alguns acontecimentos no final do século XVIII exerceram influências sobre setores da sociedade capitalista inglesa e do parlamento inglês. Uma dessas influências foi a observação de Percivall Pott sobre os meninos limpadores de chaminé. Suas observações, datadas de 1775, constataram a correlação entre essa modalidade de trabalho e o câncer de escroto em adolescentes (Brown; Thornton, 1957). Em 1778 foi promulgada uma lei inglesa sobre a questão, que não conseguiu ser colocada em prática (Feo; Martinez, 1993).
Dentre os diversos fatores que possibilitaram o pioneirismo e o sucesso britânico na instauração do modelo industrial, podemos destacar a falta de intervenção e restrições e o próprio incentivo governamental ao desenvolvimento das indústrias (Andersen, 1969; Huberman, 1984); outro fator foi "a exploração bem-sucedida do trabalho infantil” que "foi vital para o sucesso econômico da Grã-Bretanha no século XIX. Em 1821, aproximadamente 49\% da força de trabalho tinha menos de 20 anos" (United Kingdom, [201-?]). A concepção de infância como uma fase específica que requer práticas sociais diversas das do mundo adulto, como já se observava na Europa, não era uma realidade compartilhada por todas as classes sociais na Inglaterra (Ariès, 1981), mas vinha, contudo, adquirindo notoriedade e contorno à medida que a infância pobre se apresentava como um problema social. Se uma classe de crianças já se encontrava isenta do trabalho, outra, ao contrário, ainda era inserida no mundo do trabalho pela prerrogativa de benefícios propiciados simultaneamente à criança e à sociedade, pois o ingresso de crianças em atividades produtivas foi advogado por setores hegemônicos da sociedade inglesa como uma resposta ao problema da pobreza no século XVIII.

O que é necessário sublinhar é que a relação entre infância e trabalho no desenvolvimento das cidades industrializadas inglesas da segunda metade do século XVIII não inaugura a participação de crianças em atividades produtivas, porém, à medida que consolida a franca exploração do trabalho de crianças para fins de aumento da acumulação de capital, vem a fomentar simultaneamente, duas (então novas) perspectivas: a) embasa a necessidade de proteção social da infância mediante, inclusive, a intervenção estatal; e b) evidencia o caráter prejudicial das novas relações, processos, condições e ambientes de trabalho. É na agregação dessas duas novas perspectivas que se fez possível a intervenção estatal no sentido de impor regras contratuais ao trabalho (Aguiar Junior, 2015). Já em 1788, uma primeira lei, a Chimney Sweepers Act of 1788, visava a impor limites etários à exploração da mão de obra de crianças na limpeza de chaminés; muito embora, somente com a lei Chimney Sweepers Act, publicada em 1875, as regras quanto ao trabalho de crianças neste ofício conseguiriam ser aplicadas pelo Estado britânico. 
A exploração do trabalho de crianças veio se tornando um fenômeno cada vez mais notório e questionado por algumas pessoas da sociedade inglesa, gerando discussões que chegaram ao parlamento. Então, "indivíduos benevolentes fizeram o sofrimento das crianças empregadas se tornar conhecido através dos jornais públicos a partir de 1796" (Grant, 1866, p. 7). "A opinião pública pressionou o parlamento britânico e Sir Robert Peel, possuidor de fábricas, influenciou o parlamento a baixar primeira lei de proteção à saúde dos trabalhadores" (Heloani, 2011, p. 155). A Health and Moral of Apprentices Act, de 1802, visava a impor regras ao uso do trabalho dos aprendizes na indústria têxtil: a) exigia providências de higiene e salubridade nos ambientes de trabalhos, como limpeza e janelas para ventilação; b) proibia o trabalho noturno dos aprendizes; c) limitava a jornada de trabalho dos aprendizes a, no máximo, 12 horas; d) estipulava a instrução dos aprendizes em leitura, escrita e aritmética; e) determinava a nomeação de visitantes para averiguar as condições das fábricas; f) especificava que os visitantes, quando constatassem a prevalência de doenças infecciosas numa fábrica, deviam mandar que os proprietários chamassem serviços de assistência médica; g) determinava dormitórios separados para meninos e meninas, alocando no máximo dois aprendizes por cama; h) estabelecia multas ao descumprimento da lei; i) exigia que a lei fosse divulgada afixando-a nas paredes das indústrias (United Kingdom, 1802).

As providências que visavam à melhoria das condições de saúde no trabalho dos aprendizes seriam extensivas a todos os trabalhadores das indústrias têxteis que utilizassem o trabalho de aprendizes, conforme especificado na referida lei. Contrária aos interesses da maior parte dos proprietários que percebiam a intervenção legal na imposição de regramentos e a aplicação de multas ao descumprimento das regras como entraves à acumulação de capital e ao progresso econômico da sociedade - essa lei desponta como marco legal na conquista de direitos dos trabalhadores. As lutas por direitos trabalhistas que marcariam o século que se iniciava teve, na fragilidade da infância, se não seu principal motivo, o seu argumento inicial - argumento ainda estrategicamente implícito, visto que, na referida lei, a intervenção estatal tinha como objeto a saúde e a moral das crianças trabalhadoras, mas intervia tendo como base a aprendizagem.

A aprendizagem era uma relação na qual, por meio de uma Escritura de Aprendizagem, uma criança ("usualmente por volta dos 11 ou 12 anos, mas algumas vezes aos 7 anos de idade") era entregue a um mestre - por um período de sete anos em média - para que este a ela ensinasse seu ofício (London Lives, 2010). Nesse sistema, o mestre assumia a responsabilidade pela educação, alimentação e demais cuidados com os aprendizes e em troca recebiam obediência e força de trabalho. Com a nova organização produtiva britânica, a aprendizagem pôde oferecer mão de obra barata às indústrias e logo destituiu-se dos intuitos educacionais que, ao menos em tese, possuía anteriormente.

Cabe, então, destacar que a Health and Moral Act of Apprentices of 1802 não proibiu o trabalho de crianças nas indústrias têxteis, nem impôs um limite de idade para o uso de crianças aprendizes. Segundo Heloani (2011, p. 155), essa lei “por um 'lapso' absurdo, não estabelecia um limite de idade para o trabalho, permitindo que crianças extremamente pequenas trabalhassem nas fábricas". Porém, partindo da percepção de que as condições de trabalho nas indústrias eram prejudiciais à saúde e ao desenvolvimento daquelas crianças, criou juridicamente condições iniciais de exigibilidade de ações em prol da saúde dos trabalhadores - ações que, por certo, estão no cerne da luta histórica pelo direito à saúde no trabalho e que já se especificava nessa lei: a) higiene e salubridade dos ambientes de trabalho; b) limitação da jornada de trabalho; c) inspeção (vigilância por pessoa externa) das condições de trabalho; e d) intervenção de assistência médica.

As cidades industriais tinham as crianças como força de trabalho indispensável e barata. Com a lei de 1802, restrições e exigências foram impostas na utilização dos aprendizes. Porém, isso não restringiu a utilização da mão de obra de crianças, pois, manteve-se, consequentemente, o emprego de crianças da vizinhança das indústrias. Na primeira década do século XIX, um quinto dos trabalhadores nas indústrias de algodão tinha menos que 13 anos de idade (United Kingdom, [201-?]). A proximidade ou a presença de pais ou de guardiões dessas crianças 
tornava desnecessária a relação de aprendizagem e elas eram, então, empregadas, não mais como aprendizes, mas como trabalhadores. E "o estado destas crianças era tão ruim quanto o dos aprendizes” (Grant, 1866, p. 6). Alfred (1857, p. 8) destaca que a lei de 1802 "não teve outro efeito além de afastar gradualmente o emprego de aprendizes".

Sir Robert Peel, apontado como o principal nome por trás da lei de 1802 (Heloani, 2011; Vasconcellos; Oliveira, 2011), constatando que as crianças permaneciam sendo exploradas nas indústrias, iniciou um movimento em 1815 para aplicar as regras trabalhistas a crianças de "todos os tipos". E, depois de conseguir levantar evidências de abusos entre 1816 e 1818, conseguiu, em 1819, aprovar uma lei no parlamento inglês que proibia o emprego de crianças menores de nove anos nas indústrias de algodão e limitava a jornada dos menores de 16 anos a 12 horas por dia (Alfred, 1857). Porém, até a década de 1830, o governo britânico exerceu, de fato, muito pouco controle sobre o uso da mão de obra de crianças nas indústrias têxteis e mesmo depois da aprovação desta lei, o trabalho de crianças ainda foi amplamente utilizado (Jeans, 1892).

A década de 1830, na Inglaterra, pode se destacar por, pelo menos, três eventos fundamentais na configuração da atenção à saúde no trabalho: 1) o surgimento da medicina do trabalho; 2) a publicação do Factory Act of 1833; e 3) a abolição da escravatura.

1) Com a crescente intervenção do poder público no intuito de impor regras às relações trabalhistas, vinha se instituindo pouco a pouco a necessidade dos empregadores adequarem as condições de trabalho. 0 surgimento do primeiro serviço de medicina do trabalho na Inglaterra, na década de 1830 , é fruto da exigência de prevenção dos danos à saúde dos trabalhadores que o proprietário da indústria transfere como responsabilidade ao médico do trabalho (Mendes; Dias, 1991). Com a promulgação das leis das fábricas, exigências como controle e registro de idade dos empregados e proteção à saúde e à vida dos trabalhadores abrem espaço para a presença da intervenção médica nos espaços fabris. Pode-se inferir que as ações dos proprietários para preservar a saúde de seus empregados tinham um cunho protetivo da força de trabalho, mas, principalmente, erigiu-se pelas ameaças das punições legais a que poderiam ser submetidos. O título da publicação de Robert Baker - considerado o primeiro médico do trabalho - The Factory Acts made easy: or how to work the law without the risk of penalties (1854) parece evidenciar essa inferência.

2) Em 1833 o governo britânico publica uma lei sobre o trabalho nas indústrias têxteis (Factory Act of 1833), que veio a ter maior aplicabilidade que as anteriores. Essa lei: a) proibia o emprego de menores de nove anos; b) determinava que os empregadores deveriam manter um certificado de idade das crianças trabalhadoras; c) limitava o máximo de 9 horas por dia de trabalho para as crianças entre 9 e 13 anos; d) limitava o máximo de 12 horas por dia para o trabalho de crianças entre 13 e 18 anos; e) proibia o emprego de crianças no trabalho noturno; f) especificava a obrigação de duas horas de estudo por dia para as crianças; g) criava o cargo de inspetor de fábricas (United Kingdom, 1933a).

3) Nesse mesmo ano, a Inglaterra aboliu o regime de escravatura com o Slavery Abolition Act of 1833 , que tornava, a partir de $1^{\circ}$ de agosto de 1834, todo e qualquer escravo uma "pessoa livre", devendo ser "absolutamente e para sempre alforriado”. Especificava que, então, também as "crianças" desses escravos, bem como os filhos dessas "crianças", deveriam ser, de igual modo, livres desde o nascimento (United Kingdom, 1833b).

A ascensão da liberdade como um direito humano e do trabalho como um direito de pessoas livres no seio da sociedade liberal capitalista não veio a operar transformações contundentes no aspecto de subjugação contido nas relações de trabalho do sistema feudal e do regime de escravatura. Apenas reformulando-a, viria a tornar a subjugação dos trabalhadores um aspecto inescapável do direito à liberdade de comprar e vender força de trabalho. Todavia, a concepção de infância insurgiria pouco a pouco como uma exceção a esse aspecto e, assim, 
regras e limites etários viriam a ser especificado nas legislações subsequentes.

A partir da década de 1830, começa a ocorrer um declínio nas taxas de emprego de crianças. Entre 1835 e 1838 a porcentagem de crianças compondo a força de trabalho nas indústrias têxteis cai de 15,9\% para 7,9\%. Nardinelli (1980) considera a existência de duas hipóteses para esse declínio: a) a interpretação tradicional de que a redução do trabalho infantil foi atribuída ao esforço dos inspetores de fábricas de fazerem a lei ser cumprida; e b) a hipótese alternativa de que os índices de trabalho infantil já estavam declinando e as leis das fábricas apenas aceleraram as mudanças.

Apesar do relativo decréscimo que se iniciara, o emprego de crianças nas indústrias permaneceria como, se não o principal, um problema do trabalho industrial durante todo o século XIX e assunto nas principais leis das fábricas. Nas indústrias de seda, por exemplo, a porcentagem de crianças trabalhando era de $29,5 \%$ em 1835 e somente em 1890 chegaria aos 7\% (Nardinelli, 1980). Com as restrições de idade e as regras quanto à jornada de trabalho das crianças trabalhadoras, proprietários de indústrias criavam formas de burlar essas regras. Em 1832, implementava-se o emprego de crianças em double sets, turnos de seis horas que dificultavam as inspeções. "Manter um registro do complicado arranjo de horas trabalhadas por cada criança estava fora de questão. Então o abuso foi de mal a pior" (Jeans, 1892, p. 8).

A continuidade da grande parcela de crianças na composição da força de trabalho pautou, entre outras reivindicações, a luta pela redução da jornada de trabalho. Sabe-se, por exemplo, que "a regulação da jornada de trabalho, na lei de 1850, não foi somente para proteger as classes protegidas (mulheres e pessoas jovens), mas para limitar o trabalho dos homens adultos" (Jeans, 1892, p. 13).

Enquanto alguns reformadores já defendiam a ideia de que a infância era uma etapa da vida que necessitava de cuidados e proteções especiais - e, então, buscavam poupá-la da exploração no trabalho -, pensadores liberais argumentavam que o desenvolvimento industrial não podia isentar a infância do trabalho. Senior (1837), por exemplo, ao se opor à redução da jornada de trabalho, argumenta que o trabalho das crianças nas indústrias era "comparativamente leve" e que as intervenções restritivas do Estado prejudicariam o progresso industrial. As leis das fábricas eram consideradas absurdas e opressivas para os que defendiam o crescimento econômico irrestrito do sistema industrial.

Porém, a exploração irrestrita da força de trabalho de crianças nas indústrias têxteis se tornaria insustentável na sociedade inglesa, primeiramente, porque a reação humanitária tornou notório e público o prejuízo que se causava diretamente às crianças trabalhadoras e, posterior e principalmente, porque a inserção precoce no trabalho acarretava problemas aos dois polos do mercado de compra e venda da força de trabalho: a) por um lado, implicava em uma desregulação que reduzia o valor da mão de obra adulta ao possibilitar que os proprietários encontrassem nas crianças mão de obra barata, trabalhadores em abundância e com pouco ou nenhum poder de reivindicação; b) por outro lado, a continuidade irrestrita da intensa exploração das crianças viria a prejudicar em médio e longo prazos a reprodução da força de trabalho. Como Althusser (1974) observa, "a condição última da produção é, portanto, a reprodução das condições da produção" (p. 9) e "a reprodução da força de trabalho passa-se essencialmente fora da empresa" (p. 18).

Discursos médicos e pedagógicos já sustentavam argumentos sobre características específicas da infância que carecem de ações em prol do desenvolvimento mais pleno possível, mas parece ter sido a organização do novo modo de produção industrial urbano que, de fato, demonstrou a necessidade da intervenção do poder público na garantia das condições de saúde e educação das crianças das cidades industriais. Redgrave (1895, p. 9) relembra que "o movimento em 1802 era sanitário, bem como educacional. A influência das leis das fábricas foi o primeiro passo para a melhoria sanitária, culminando numa legislação subsequente para a saúde das cidades”. Mais do que simplesmente a proteção da infância em si, a intervenção estatal que impunha regras ao trabalho de crianças na Grã-Bretanha propiciou as bases do ordenamento jurídico trabalhista, denotando a saúde como um direito do trabalhador. Garantir a saúde da classe trabalhadora, consequentemente a “adequada” exploração e reprodução da força de tra- 
balho, passaria a se consolidar como uma atribuição do Estado. Consequentemente, uma medicina social começou a se instaurar na Inglaterra, influenciada pela necessidade de preservação e manutenção da saúde da classe pobre trabalhadora (Foucault, 2002). As crianças pobres, pouco a pouco, passariam a receber maior atenção do poder público, a partir do regramento do mundo do trabalho industrial.

As intervenções jurídicas do estado britânico referentes ao emprego de crianças precedem as relativas à educação. Inclusive, é na intervenção sobre o trabalho de crianças que se começa a instituir a obrigatoriedade da educação escolar para as crianças trabalhadoras e, com a crescente retirada das crianças das fábricas, a escolaridade vai se tornando cada vez mais necessária, até ser consolidada a sua obrigatoriedade. A educação das crianças, responsabilidade de seus tutores legais, passaria a ser pouco a pouco assumida como incumbência do Estado.

A organização econômica britânica veio, ainda no século XIX, a influenciar os demais Estados europeus. Na Irlanda, por exemplo, a Elementary Education Act of 1876, que dispôs ao mesmo tempo "sobre o emprego e a educação das crianças", especificava que era obrigação dos pais fazer que os filhos recebessem instrução em escrita, leitura e aritmética, e que era proibido o emprego de qualquer criança com menos de dez anos. Entretanto, abria exceções à proibição do emprego: as crianças poderiam ser empregadas desde que não se prejudicasse sua saúde e educação; e a autoridade local poderia revogar a proibição de lei, permitindo que crianças acima dos oito anos fossem empregadas para colheita e criação, num período máximo de seis semanas por ano (United Kingdom, 1876). Essa lei - que abria exceções aos pais, por razões de pobreza, quanto ao pagamento de taxa à escola pública - visava a ampliar a escolarização e a proibir o emprego, mas levava em conta certas demandas de participação de crianças no trabalho das famílias rurais. Parece evidente que, mais do que o trabalho em si, a condição de exploração econômica da força de trabalho das crianças nas indústrias açoitava sua saúde e integridade - exploração essa que impunha ritmos, jornadas e condições ao processo de trabalho que incutia agravos à saúde de todos os trabalhadores, mas que, evidentemente, as crianças - por suas características de desenvolvimento fisiológico, psíquico e moral - estiveram (e estão) mais suscetíveis.

Graça (1999) relembra que no início do século XIX as conquistas legais em prol de melhores condições de trabalho ocorreram nem tanto pela luta do movimento operário - que nessa época ainda não era organizado -, mas em razão da influência de filantropos, reformadores e humanistas. Dessa forma, a perspectiva humanística de proteção da infância que florescia na Europa permeou as principais intervenções em favor da saúde no trabalho na promulgação das primeiras leis britânicas das fábricas.

Evidentemente que a questão da exploração do trabalho de crianças se tornou uma pauta central da classe trabalhadora, que não se absteve de reivindicar, a partir da perceptível e relativa fragilidade das crianças, limites a tal exploração na luta pelo direito à saúde no trabalho. Contudo, se o atual Direito Internacional do Trabalho tem nas legislações inglesas (Factory Acts) o seu marco jurídico inicial de regramentos contratualistas na relação de compra e venda da força de trabalho, o direito à saúde no trabalho tem no alvorecer da concepção moderna de infância o seu alicerce, muito embora, posteriormente, a infância viesse a ser, juridicamente, apartada do mundo do trabalho.

Apesar das restrições etárias terem, inegavelmente, cunho protetivo, o processo de proibição e retirada de crianças do trabalho nas indústrias não lhes garantiu, necessariamente, maior proteção. Livres das agruras do trabalho industrial, a fome, o abandono e demais consequências da miséria continuavam ainda a solapar a vida de muitas crianças; ademais, há a hipótese de que as crianças que foram proibidas de trabalhar nas fábricas teriam sido empregadas em outros tipos de trabalho (Nardinelli, 1980; Corsaro, 2011; Humphries, 2013). É somente no século XX que a proteção à infância, como um direito de toda e qualquer criança, começaria a florescer no cenário internacional, mas observamos que, com a publicação de duas leis - Children's Dangerous Act de 1879 e Prevention to cruelty, and better protection of children Act de 1889 - no último quarto do século XIX a preocupação com o tratamento que a sociedade inglesa destinava às crianças começou a extrapolar a questão de retirá-las do trabalho industrial. Verificamos que a concepção de infância que já se configu- 
rava como uma representação social na Europa tinha bases filosóficas, pedagógicas e sociais; entretanto, juridicamente, o conceito de infância (e da necessidade de se protegê-la) foi posterior e inegavelmente influenciado pelos regramentos do trabalho.

A concepção de infância serviu para ressaltar a exploração ilimitada que a organização do trabalho no sistema industrial capitalista vinha impondo, além de denunciar que a ausência de regras protetivas da força de trabalho implicaria na perda da saúde e vida dos trabalhadores e prejudicaria, em médio e longo prazos, a própria reprodução da força de trabalho. Foi, então, fundamentada nessa concepção que se instaurariam as primeiras intervenções de imposição de regras ao mundo do trabalho, consolidando, aos poucos, a saúde como um direito da classe trabalhadora, ainda hoje não contemplado devidamente em sua plenitude.

\section{Considerações finais}

Passados mais de dois séculos da publicação da Health and Moral Act of 1802, o fenômeno da exploração da força de trabalho infantil ainda se apresenta como um problema mundial de proporções alarmantes. Partindo de uma reflexão crítica, podemos compreender que a proposta de proibição e as políticas de erradicação do trabalho infantil, se por um lado denotam uma preocupação com a vida e a saúde de crianças e adolescentes, por outro evidenciam a extrema dificuldade de seu êxito. As dimensões do problema nos servem tanto para sublinhar as graves dificuldades da organização social do trabalho que ainda vigem no mundo e que prosseguem açoitando a saúde e a vida de trabalhadores de todas as idades quanto para refletirmos sobre as formas como se tem buscado enfrentar esse problema.

Por que ainda há tantas crianças e adolescentes trabalhando e, ao mesmo tempo, tantos adultos que não conseguem trabalho? Por que ainda há condições de trabalho tão desumanas e degradantes? Essas e tantas outras perguntas demonstram o quanto a questão das relações entre a infância e o trabalho é de fato complexa. A exploração do trabalho infantil precisa ser combatida com a devida ênfase e urgência. Entretanto, faz-se necessária uma compreensão mais ampla da relação entre infância e trabalho para que sejam possíveis ações mais efetivas referentes aos direitos das crianças e adolescentes e, também, ao direito à saúde dos trabalhadores.

Neste artigo, rememorou-se e enfatizou-se a importância social e histórica que a infância teve (e ainda tem) para as (re)configurações do mundo do trabalho. Dessa forma, pretendeu-se atribuir o devido reconhecimento e respeito à participação de crianças e adolescentes na história do direito à saúde no trabalho, apontando que a produção de conhecimentos e de intervenções sobre as relações saúde-trabalho ainda pode e deve ampliar a sua compreensão sobre a relação entre a infância e o mundo do trabalho.

\section{Referências}

AGUIAR JUNIOR, V. S. Infância, trabalho e saúde: reflexões histórico-teórico-conceituais sobre o discurso oficial. 2015. Dissertação (Mestrado em Saúde Pública) - Escola Nacional de Saúde Pública Sérgio Arouca, Rio de Janeiro, 2015.

ALFRED. The History of the factory movement: from the year of 1802, to the enactment of the ten hours' bill in 1847. London: Simpkin, Marshall \& Co., 1857. (Volume II).

ALTHUSSER, L. Ideologia e aparelhos ideológicos do Estado. Lisboa: Editorial Presença, 1974.

ANDERSEN, W. O. A Revolução Industrial. Lisboa: Editores Associados, 1969.

ARIÈS, P. História social da criança e da família. Rio de Janeiro: Guanabara, 1981.

BAKER, R. The Factory Acts made easy: or how to work the law without the risk of penalties. Leeds: H. W. Walker, 1854 .

BRASIL. Lei no 8.069, de 13 de julho de 1990.

Dispõe sobre o Estatuto da Criança e do Adolescente e dá outras providências. Diário Oficial [da] República Federativa do Brasil, Brasília, DF, 27 set. 1990. Disponível em: <https:// goo.gl/XEght>. Acesso em: 18 jan. 2016.

BROWN, J. R.; THORNTON, J. L. Percivall Pott (1714-1788) and chimney sweepers' cancer of the scrotum. British Journal of Industrial Medicine, London, v. 14, n. 1, p. 68-70, 1957. 
CORSARO, W. A. Sociologia da infância. Porto

Alegre: Artmed, 2011.

FEO, O. I.; MARTINEZ, M. C. Cáncer ocupacional: epidemiología y prevención. Salud de los trabajadores, Valencia, v. 1, n. 2, p. 109-199, 1993.

FOUCAULT, M. Microfísica do Poder. Rio de Janeiro: Graal, 2002.

GRAÇA, L. Promoção da saúde no trabalho: a nova saúde ocupacional? Lisboa: Sociedade Portuguesa de Medicina do Trabalho, 1999.

GRANT, P. The Ten Hours' Bill: The History of Factory Legislation, step by step, since its introduction to parliament by the first Sir Robert Peel, in 1802, till it was finally carried by Lord Ashley, in 1850, together with many incidents, letters, speeches... Manchester: J. Heywood, 1866.

HELOANI, J. R. Saúde mental no trabalho: algumas reflexões. In: MENDES, A. M. (Org.). Trabalho e saúde: o sujeito entre emancipação e servidão. Curitiba: Juruá, 2011. p. 151-162.

HUBERMAN, L. História da riqueza do homem. Rio de Janeiro: Zahar, 1984.

HUMPHRIES, J. Childhood and child labour in the British industrial revolution. Economic History Review, London, v. 66, n. 2, p. 395-691, 2013.

JEANS, V. Factory Act Legislation: it's industrial and commercial effects, actual and prospective. London: T. Fisher Unwin, 1892.

LIBERATI, W. D.; DIAS, F. M. D. Trabalho infantil. São Paulo: Malheiros, 2006.

LONDON LIVES. Apprenticeship indentures and disciplinary cases. 2010. Disponível em: <http:// bit.ly/2mPh5wn>. Acesso em: 14 jan. 2016.

MARX, K. O Capital: crítica da economia política. Livro I: Processo de Produção do Capital. Rio de Janeiro: Bertrand Brasil, 1988.

MENDES, R.; DIAS, E. C. Da medicina do trabalho à saúde do trabalhador. Revista de Saúde pública, São Paulo, v. 25, n. 5, p. 341-349, 1991.

NARDINELLI, C. Child labor and factory acts. The Journal of Economic History, Cambridge, v. 40, n. 4, p. 739-755, 1980.
OIT - ORGANIZAÇÃO INTERNACIONAL DO TRABALHO. Convenção $n^{\circ} 182$ sobre a proibição das piores formas de trabalho infantil e a ação imediata para a sua eliminação. Brasília, DF, 1999. Disponível em: <https://goo.gl/59uRPg>. Acesso em: 18 jan. 2016.

OIT - ORGANIZAÇÃO INTERNACIONAL DO TRABALHO. Documento Base para III Conferência Global sobre Trabalho Infantil, Brasília, DF, 2013. Disponível em: <https://goo.gl/VwKlPa>. Acesso em: 18 jan. 2016.

POSTMAN, N. O Desaparecimento da infância. 2. ed. Rio de Janeiro: Graphia, 2012.

QVORTRUP, J. A infância enquanto categoria estrutural. Educação e Pesquisa, São Paulo, v. 36, n. 2, p. 631-643, 2010.

QVORTRUP, J. Nove teses sobre a "infância como um fenômeno social”. Pro-Posições, Campinas, v. 22, n. 1, p. 199-211, 2011 a.

QVORTRUP, J. A volta do papel das crianças no contrato geracional. Revista Brasileira de Educação, Rio de Janeiro, v. 16, n. 47, 2011b.

REDGRAVE, A. The Factory acts by the late Alexander Redgrave. London: Shaw \& Sons, 1895.

UNITED KINGDOM. Health and moral of apprentices act: an act for the preservation of the health and morals of apprentices and others, employed in cotton and other mills, and cotton and other factories. London, 1802. Disponível em: <https://goo.gl/jjNroI>. Acesso em: 15 jan. 2016.

UNITED KINGDOM. Factory Act. London: Parliament of UK, 1833a. Disponível em: <https:// goo.gl/RQDxHn>. Acesso em: 14 jan. 2016.

UNITED KINGDOM. Slavery Abolition Act. London: Parliament of UK, 1833b. Disponível em: <https://goo.gl/YLZEFb>. Acesso em: 16 jan. 2016.

UNITED KINGDOM. Elementary Education Act, 1876: an act to make further provision for elementary education. London, 1876. Disponível em: <https://goo.gl/iP80kL〉. Acesso em: 12 jan. 2016.

UNITED KINGDOM. The National Archives. The struggle for democracy: child labor. London, 
[201-?]. Disponível em: <https://goo.gl/siglRB>. Acesso em: 5 jan. 2016.

SANTOS, R. L. Dignidade humana da criança e do adolescente e as relações de trabalho. Boletim Científico ESMPU, Brasília, DF, v. 6, n. 24/25, p. 11-38, 2007.

SENIOR, N. W. Letters on the factory act, as it affect the cotton manufacture, addressed to the right honourable. London: B. Fellowes, 1837.
STEARNS, P. N. Infância: história mundial. São Paulo: Contexto, 2006.

VASCONCELLOS, L. C. F.; OLIVEIRA, M. H. B. (Org.). Saúde, trabalho e direito: uma trajetória crítica e a crítica de uma trajetória. Rio de Janeiro: EDUCAM, 2011.

VIANNA, G. C. Direito infanto-juvenil: teoria, prática e aspectos multidisciplinares. Rio de Janeiro: Freitas Bastos, 2004.

\section{Contribuição dos autores}

Aguiar Junior concebeu e utilizou dados de sua dissertação de mestrado e de pesquisa de doutorado em andamento. Vasconcellos orientou as reflexões e participou da estruturação do artigo.

Recebido: 26/01/2016 Reformulado: 10/12/2016

Aprovado: 31/01/2017 